\title{
Impact of Climate and Bioclimate Factors on Apricot (Prunus armeniaca L.) Yield to Increase Economy and Achieve Maintaining Food Security of Palestine
}

\author{
Jehad M. H. Ighbareyeh ${ }^{1,2^{*}}$, Eusebio Cano Carmona ${ }^{2}$ \\ ${ }^{1}$ Department of Plant Production and Protection, Faculty of Agriculture, Al-Quds Open University, Hebron, Palestine \\ ${ }^{2}$ Department of Animal and Plant Biology and Ecology, Faculty of Experimental Sciences, University of Jaen, Jaen, Spain \\ Email: *jehadighbareyeh@hotmail.com
}

How to cite this paper: Ighbareyeh, J.M.H. and Carmona, E.C. (2017) Impact of Climate and Bioclimate Factors on Apricot (Prunus armeniaca L.) Yield to Increase Economy and Achieve Maintaining Food Security of Palestine. Open Access Library Journal, 4: e4119.

https://doi.org/10.4236/oalib.1104119

Received: November 5, 2017

Accepted: December 18, 2017

Published: December 21, 2017

Copyright $\odot 2017$ by authors and Open Access Library Inc.

This work is licensed under the Creative Commons Attribution International License (CC BY 4.0).

http://creativecommons.org/licenses/by/4.0/

\begin{abstract}
Apricot (Prunus armeniaca L.) is one of the most important export crops in Hebron of Palestine. In this work, we analyzed the mean monthly temperature and precipitation using data from one weather station of the Palestine Meteorological Department, recorded in the period from 1993-2014, with the same years of plant production (rain-fed) from the Palestinian Central Bureau of Statistics (PCBS). Statistical analysis included a bioclimatic analysis of Palestinian meteorological station for the period previous by using bioclimatic classification of the Earth of Rivas Martinez Salvador, with regard to simple continentality index, compensated thermicity index, annual ombrothermic index, water deficit and soil water reserve. In concluded, climate and bioclimatic factors play a key role in apricot production, when we analyzed of variance (ANOVA), with a standard coefficients (95\% confidence interval), reveals significant differences, in case of the bioclimate factors as simple thermicity index and climate factors as precipitation, whereas there are no significant differences between the apricot yield and the reset of climate, bioclimate factors. However, the optimum of the plant production is achieved with values of simple thermicity index between (14 - 18), annual ombrothermic index (2.5 - 4.5), compensated thermicity index $(250$ - 450), precipitation more than $750 \mathrm{~mm}$, mean monthly temperature $\left(15.4^{\circ} \mathrm{C}-20^{\circ} \mathrm{C}\right)$, and inframediterranean, thermomediterranean and mesomediterranean of thermotype in $\mathrm{He}$ bron of Palestine.
\end{abstract}

\section{Subject Areas}

Plant Science 


\section{Keywords}

Palestine, Hebron, Bioclimate, Biology, Climate, Yield

\section{Introduction}

Apricot (Prunus armeniaca L.) is a tree that bears the fruit of several species in the genus Prunus (stone fruits). It is belong to the Rosaceae family, the native is somewhat uncertain, though almost certainly somewhere in Asia, it was known in Armenia during ancient times, an archaeological excavation at Garni in Armenia found apricot seeds in an Eneolithic-era site [1]. It can grow in Mediterranean climates if enough cool winter weather allows a proper dormancy, a dry climate is good for fruit maturation, the tree is tolerating winter temperatures as cold as $-30^{\circ} \mathrm{C}$, spring frost has impact on apricot because it tends to flower very early, meaning spring frost can kill the flowers, and thus affect the biological life of the plant, such as biology, physiology, growth and yield. Furthermore, trees are sensitive to temperature changes during the winter season, and quite a big amount of the production is in the continental climates, and safely grown in the Mediterranean Basin countries.

However recent studies have found the impact of bioclimate and climate factors on yield, harvesting time, planting and flowering of apricot [2] [3] [4] [5], and have highlighted the influence of bioclimatology and climatology applied on biology, physiology, yield and growth of plant [3]-[22].

Many studies have been shown in 2013, that Turkey, Italy, Iran, Uzbekistan, Algeria and others countries have a high production of apricots in the world [23]. In Palestine, agriculture sector is still a relatively important, the total value of agricultural production during the agricultural year 2007/2008 approximately US $\$ 6.366,1$ million distributed $9.60 \%$ of plant production, apricot production has reached 350 tons in Hebron almost in 2008/2009 [24]. Nevertheless, Hebron has a Mediterranean climate with mild and rainy winters, it has represented the Mediterranean bio-geographical ecosystem, and Hebronbioclimatic belt belong to the inframediterranean, thermomediterranean and Mesomediterraneanof thermotype and arid, semiarid, dry, sub-humid and humid ombrotype [4].

The objective of the study is to find the relationship between the influence of bioclimatic, climatic factors on apricot production to contribute and increase the production of Apricot in Hebron, and to increase the Palestinian national economy and for the participation in the development of strategic agricultural policy.

\section{Materials and Methods}

\subsection{Study Area}

Hebron is located between longitudes $35^{\circ} 05^{\prime}$ East and latitudes $31^{\circ} 32^{\prime}$ North, rises from $700-1000$ meters above sea level, and cover an area of $74.102 \mathrm{~km}^{2}$. 
The geographic location of Hebron plays a major role in affecting the features of its climate and the biodiversity.

\subsection{Data Analysis}

Bioclimate indicators are directly related to plant physiological processes determining productivity [5]-[12] [25], and there have been several more recent classifications using bioclimate indicators to model terrestrial ecosystem distributions [26], they are now mainly used in modeling the impacts of climate change on vegetation [27] [28], and bioclimate classification of the earth [29].

However, data were used from the meteorological station of Hebron for the years 1993 to 2014, (Figure 1) and for the same years for production of plant (Table 1). The study analyzed the relationship between bioclimate, climate factors (independent variables) and apricot yield (dependent variable) by using time series data belong to the climate variables such as mean monthly temperature $(\mathrm{T})$, precipitation $(\mathrm{P})$, soil water reserve $(\mathrm{R})$, and deficit water $(\mathrm{Df})$ during the time period of 1993-2014; and bioclimate factors as annual ombrothermic index (Io), simple continentality index (Ic), and compensated thermicity index (It/Itc), these factors were obtained according methodology of Salvador Rivas-Martinez [29] [30] [31] [32] [33], nevertheless we used the following formulas to calculate the values of the various index Rivas Martínez [29] [30], annual

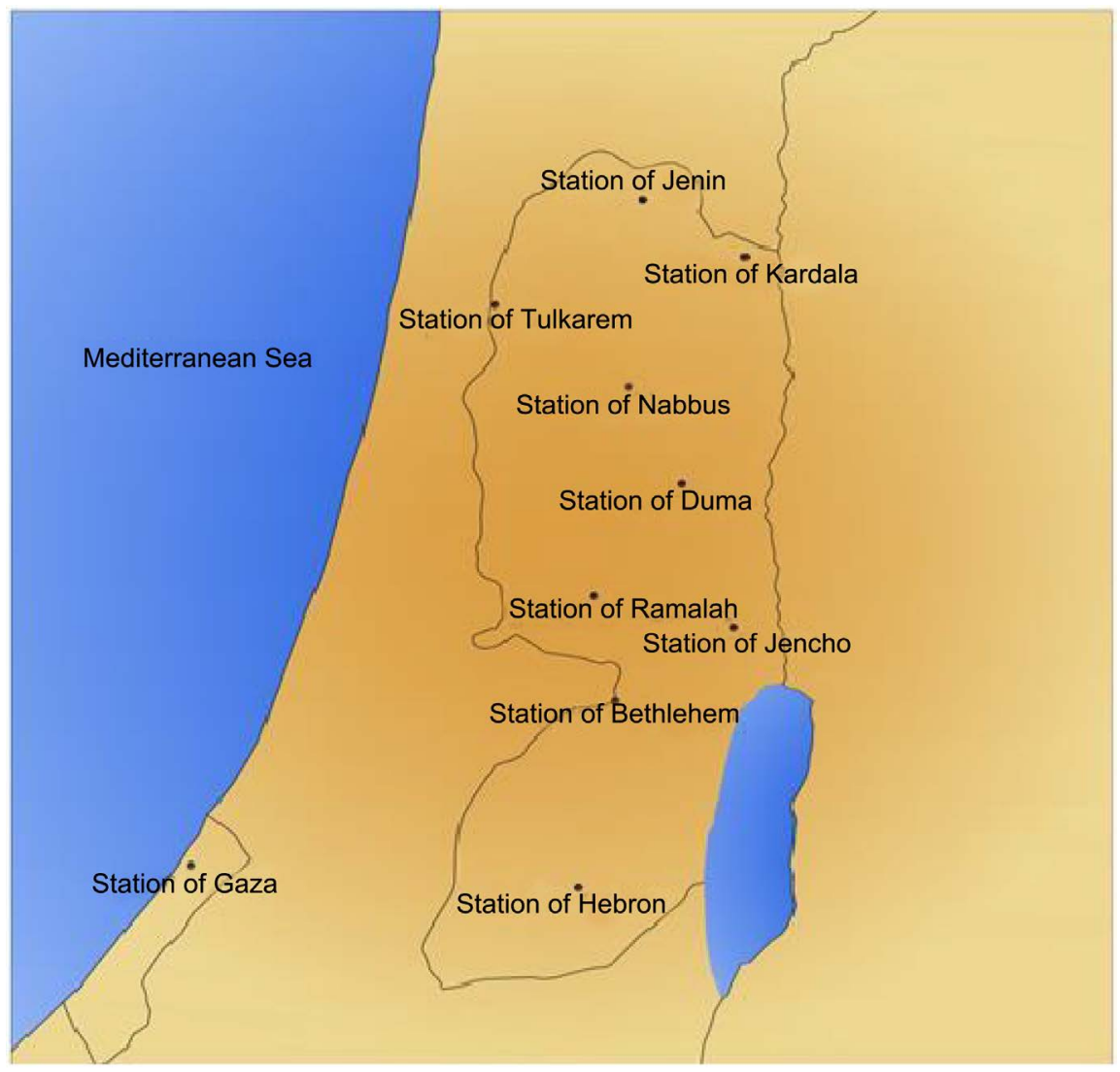

Figure 1. Location of the meteorological Palestinian stations. 
Table 1. Represents of the variables, independents variables (Climate and bioclimate factors) and dependent factors (Plant production) from 1993-2014.

\begin{tabular}{ccccccccc}
\hline Years & T & P & Df & R & It/Itc & Ic & Io & $\begin{array}{c}\text { Production of } \\
\text { apricot }\end{array}$ \\
\hline $1993-1998$ & 16.2 & 601 & 650 & 430 & 298 & 18.1 & 2.9 & 305 \\
$1998-2002$ & 16.4 & 595 & 608 & 420 & 311 & 17.6 & 3.3 & 380 \\
$2002-2006$ & 16.5 & 596 & 570 & 455 & 350 & 17.3 & 3.1 & 340 \\
$2006-2014$ & 16.8 & 595 & 611 & 411 & 400 & 17.7 & 3.0 & 350 \\
\hline
\end{tabular}

Yield: Kg. dunum; T: Mean monthly temperature; P: precipitation; R: Soil water reserve; Df: Deficit water; Io: Annual ombrothermic index; Ic: Simple continentality index; and It/Itc: Compensated thermicity index.

ombrothermic index, Io $=\mathrm{Pp} / \mathrm{Tp}$; bimonthly summer ombrothermic index, Is $2=$ $\mathrm{P}$ July + August/T July + August; trimonthly summer ombrothermic index, Is3 = $\mathrm{P}$ June + July + August/T June + July + August; and continentality index, Ic = Tmax - Tmin; thermicity index, or where applicable compensated thermicity index, $\mathrm{It} / \mathrm{Itc}=(\mathrm{T}+\mathrm{M}+\mathrm{m}) 10 . \mathrm{Pp}=$ positive precipitation and $\mathrm{Tp}=$ positive temperature (in this case equivalent to annual precipitation and average annual temperature divided by 12 , as all the months have an average temperature above $\left.0^{\circ}\right) ; \mathrm{P}=$ precipitation of the months indicated; $\mathrm{T}=$ average temperature of the months indicated; Tmax $=$ maximum temperature of the averages of the warmest month of the year; Tmin = minimum temperature of the averages of the coldest month of the year; $\mathrm{T}=$ average annual temperature; $\mathrm{M}=$ average of the maximum temperature of the coldest month of the year; and $\mathrm{m}=$ average of the minimum temperature of the coldest month of the year.

Moreover, in this study, the Shapiro-Wilk and Jarque-Bera normality tests were applied [34] [35] [36] [37], and the p-value was obtained for the seven variables. We applied analysis of variance (ANOVA) linear regression analysis to each of the eight variables (independent and dependent variables), the three bioclimatic variables (Io, Ic and It/Itc) and the four remaining physical variables as (climate factors), and the dependent variable (apricot production)to obtain the Pearson's correlation matrix and the principal component analysis (PCA) were subsequently applied and find the correlation between variables and factors and to determine the influence of independent variables on production, and these statistical analyses were done using the XLSTAT software.

\section{Results and Discussion}

However, we used the bioclimatic classification of earth to Salvador Rivas-Martinez to analyses of the climate factors and bioclimatic parameters (independent variables), Rivas Martinez methodology [30], determines a generic world-wide climate classification in five macrobioclimates (tropical, Mediterranean, temperate, boreal and polar) on the basis of bioclimatic indexes. We indicated that the p-value obtained from the variables studied tended to be below 0.05 , a conventionally accepted value, after application of the Shapiro-Wilk normality test [34] [35]. 


\subsection{Analysis of Pearson's Correlation Matrix}

The correlation coefficient is always between -1 and +1 , the closer the correlation is to $+/-1$, the closer to a perfect linear relationship in analysis, therefore if the correlation coefficient is equal $(-1.0$ to -0.7 a strong negative association, -0.7 to -0.3 weak negative association, -0.3 to +0.3 little or no association, +0.3 to +0.7 weak positive association, and +0.7 to +1.0 strong positive association), and the $\mathrm{p}$-value was obtained with statistically significant $(\mathrm{P}=0.05)$. However a correlation is a number between -1 and +1 that measures the degree of association between two variables, and Pearson correlation was developed by Karl Pearson from a related idea introduced by Francis Galton in the 1880s [38] [39] and the formula for the Pearson correlation is computed as:

$$
r=\frac{\sum_{i=1}^{n}\left(X_{i}-\bar{X}\right)\left(Y_{i}-\bar{Y}\right)}{(n-1) S_{X} S_{Y}}
$$

According of the analysis in (Table 2) shows the Pearson's correlation matrix between the variables studied, precipitation (0.974), annual ombrothermic index $(0.919)$ and simple continentality index $(0.890)$ were strong positive correlated to yield and growth activates of plant, a positive value for the correlation implies a positive association between the factors previous (P, Io and Ic) and the plant, whereas mean monthly temperature, deficit water, soil water reserve, and compensated thermicity index were negatively correlated between different variables, a negative value for the correlation implies a negative or inverse association between the factors of (T, R, Df and It/Itc) and the plant activities as growth, yield, sustainability, and a high correlation negatively was observed with mean monthly temperature $(-0.953)$, deficit water $(-0.705)$, soil water reserve $(-0.300)$ and compensated thermicity index $(-0.579)$. In the other hand, the correlation coefficient is a strong negative association or significance in case of the mean monthly temperature $(-0.959)$ because correlation coefficient value is closed to -1 and weak negative association with the factors of deficit water, soil water reserve and compensated thermicity index.

Table 2. Pearson's correlation matrix between the different variables.

\begin{tabular}{ccccccccc}
\hline Variables & T & $\mathbf{P}$ & Df & $\mathbf{R}$ & It/Itc & Ic & Io $\begin{array}{c}\text { Production } \\
\text { of apricot }\end{array}$ \\
\hline $\mathrm{T}$ & $\mathbf{1}$ & -0.955 & 0.638 & 0.174 & 0.401 & -0.980 & -0.964 & -0.953 \\
$\mathrm{P}$ & -0.959 & $\mathbf{1}$ & -0.555 & -0.454 & -0.674 & 0.861 & 0.844 & 0.974 \\
$\mathrm{Df}$ & 0.638 & -0.555 & $\mathbf{1}$ & -0.380 & 0.012 & -0.683 & -0.787 & -0.705 \\
$\mathrm{R}$ & 0.174 & -0.454 & -0.380 & $\mathbf{1}$ & 0.915 & 0.004 & 0.083 & -0.300 \\
Itc & 0.401 & -0.674 & 0.012 & 0.915 & $\mathbf{1}$ & -0.208 & -0.178 & -0.579 \\
Ic & -0.980 & 0.861 & -0.683 & 0.004 & -0.208 & $\mathbf{1}$ & 0.988 & 0.890 \\
Io & -0.964 & 0.844 & -0.787 & 0.083 & -0.178 & 0.988 & $\mathbf{1}$ & 0.919 \\
Apricot & -0.953 & 0.974 & -0.705 & -0.300 & -0.579 & 0.890 & 0.919 & 1 \\
production & & & & & & & &
\end{tabular}




\subsection{Principal Component Analysis}

Principal component analysis (PCA) is a useful statistical technique that has found application in fields such as face recognition and image compression, and is a common technique for finding patterns in data of high dimension, it covers standard deviation, covariance.

\section{Correlations Coefficient between Variables and Factors}

In this study, we applied correlation coefficient between variables and factors, the correlation coefficient is constrained for fall in the range \pm 1 . A value of +1 tells us that the points (xi, yi) define a straight line with a positive slope. A value of -1 tells us that the points (xi, yi) define a straight line with a negative slope. A value of 0 shows that there is no dependence of $y$ on $x$ or vice versa (no correlation), and the $\mathrm{p}$-value was obtained with statistically significant $(\mathrm{P}=0.05)$. Moreover, in the (Table 3 ) shows the factor 1 was correlated by climate factors as precipitation (0.972) and bioclimate factors as annual omrothermic index (0.950) and simple continentality index (0.936), except compensated thermicity index is a negatively (0.492), and these factors were located at the left of axes F1 with accounts variance $(70.10 \%)$ as in (Figure 2). Factor 2 is a high correlated by

Table 3. Correlations coefficient between variables and factors.

\begin{tabular}{cccc}
\hline Variables & F1 & F2 & F3 \\
\hline T & -0.982 & -0.056 & -0.170 \\
P & 0.972 & -0.239 & 0.017 \\
Df & -0.709 & -0.531 & 0.464 \\
R & -0.227 & 0.972 & -0.053 \\
Itc & -0.492 & 0.841 & 0.233 \\
Ic & 0.936 & 0.235 & 0.239 \\
Io & 0.950 & 0.310 & 0.105 \\
Apricot production & 0.992 & -0.088 & -0.076 \\
\hline
\end{tabular}

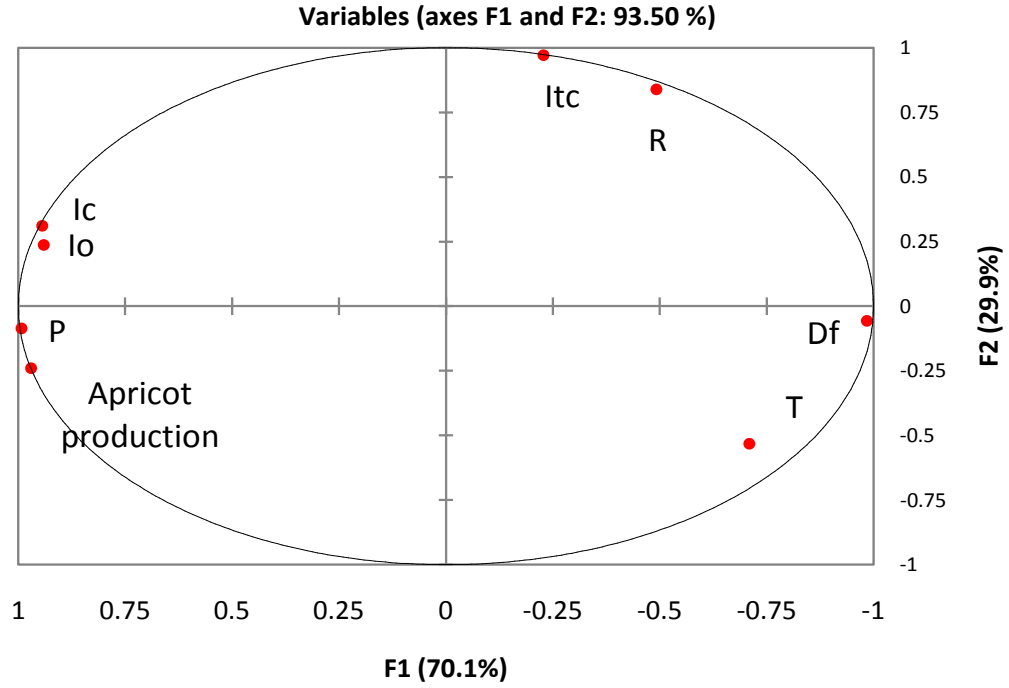

Figure 2. Graphic of principal component analysis to correlations between variables and factors. 
soil water reserve (0.972), and bioclimate factors as annual omrothermic index (0.310) and simple continentality index (0.235) and compensated thermicity index (0.841), with a large proportion of the variance explained by axes F1 and F2 (93.50\%) (Figure 2), but the rest of factors were correlated negatively because the tendency in the straight line of the variables was negative and below the $y$-axis, therefore this confirms that these variables have a negative impact on the production of apricot. Factor 3 is a high correlated by precipitation, deficit water, annual ombrothermic index, simple continentality index and compensated thermicity index, while negatively correlated by soil water reserve and mean monthly temperature and these factors were located at the right of axes F2 with accounts variance $(29.90 \%)$.

Moreover, we observed that the variables that located in the area of the $\mathrm{x}$-axis and above $y$-axis was a slope straight line for these variables positive meaning that it has a positive effect on the production of apricot, unlike variables that have occurred under the $\mathrm{y}$-axis was negative, $\mathrm{F} 1$ is a positively affected by precipitation, simple continentality index and annual ombrothermic index on plant yield and a high correlated.

\subsection{Analysis of Variance (ANOVA) and Multiple Regression Analysis}

Analysis of variance (ANOVA), with a standard coefficients (95\% confidence interval), applied to each of the apricot production, with the seven independent variable factors (T, P, R, Df, Io, Ic and It/Itc), reveals significant differences, in case of the bioclimate factors as simple thermicity index with the value (0.896) (Figure $3(\mathrm{a})$ ) because the histograms were positive and regression coefficient positively $\mathrm{R}^{2}(0.803)$ (Figure $3(\mathrm{~b})$ ), and climate factors as precipitation with the value (0.984) (Figure $3(c)$ ) and regression coefficient $R^{2}$ positively (0.903), whereas there are no significant differences between the apricot yield and the reset of climate, bioclimate factors as compensated thermicity index $(-0.579)$, because the histograms were a negativeand regression coefficient $R^{2}(0.335)$ and climate factor as deficit water $(-0.659)$ and regression coefficient $R^{2}(0.483)$ (Figures $3(\mathrm{~d})-(\mathrm{g}))$.

\section{Conclusions}

The climate and bioclimatic factors were influenced on apricot production and economic of Hebron, when we analyzed of variance (ANOVA), with a standard coefficients (95\% confidence interval), reveals significant differences, in case of the bioclimate factors as simple thermicity index and climate factors as precipitation, whereas there are no significant differences between the apricot yield and the reset of climate, bioclimate factors as compensated thermicity index and climate factor as deficit water.

The optimum of the plant production is achieved with values of simple thermicity index between (14 - 18), annual ombrothermic index (2.5 - 4.5), compensated thermicity index $(250-450)$, precipitation more than $750 \mathrm{~mm}$, mean 
Ic / Standardized coefficients

(95\% conf. interval)

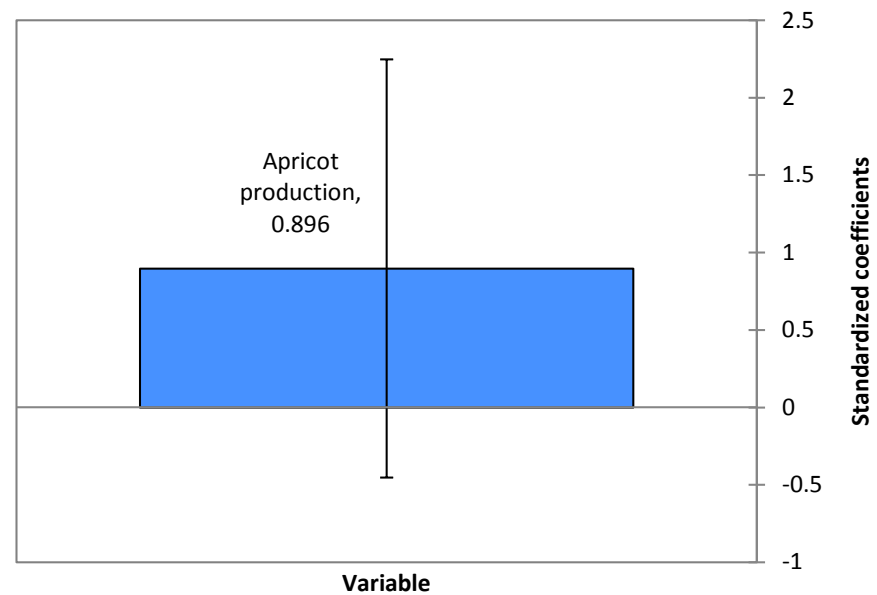

(a)

Regression of Ic by Apricot production $\left(R^{2}=0.803\right)$

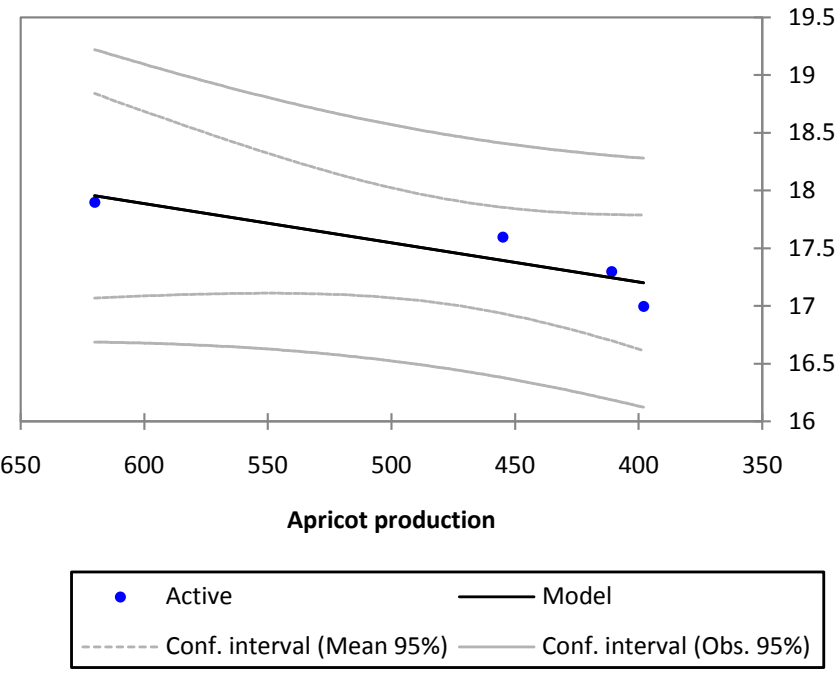

(b)

P / Standardized coefficients ( $95 \%$ conf. interval)

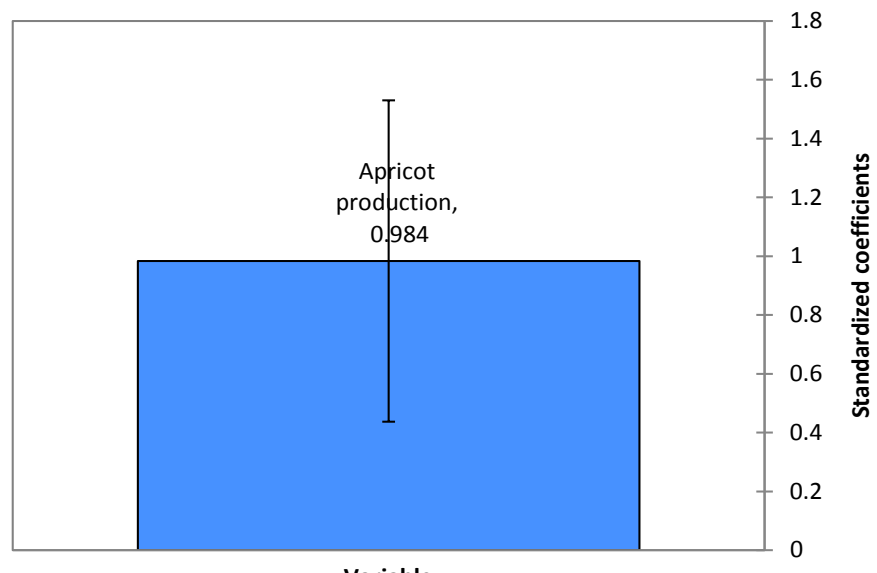

Variable

(c) 
Itc / Standardized coefficients

( $95 \%$ conf. interval)

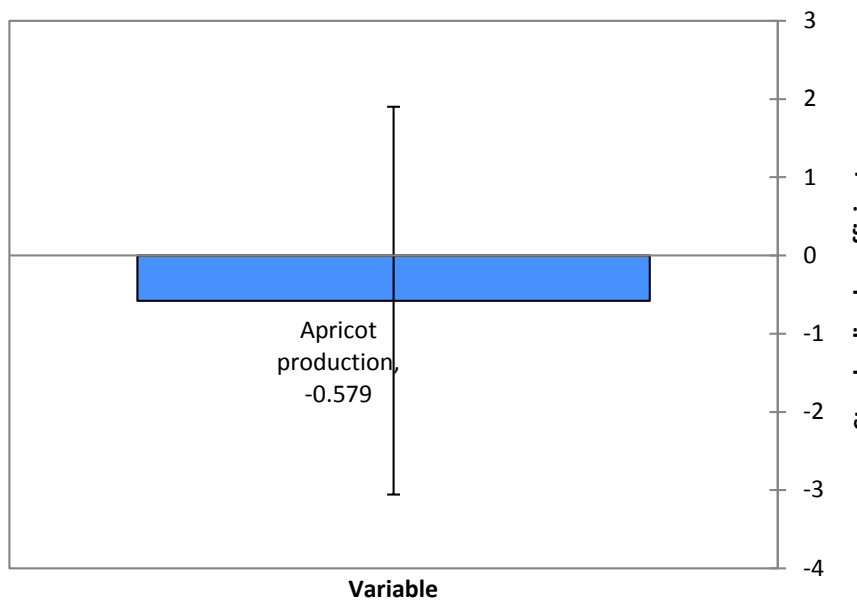

(d)

Regression of Itc by Apricot production $\left(R^{2}=0.335\right)$

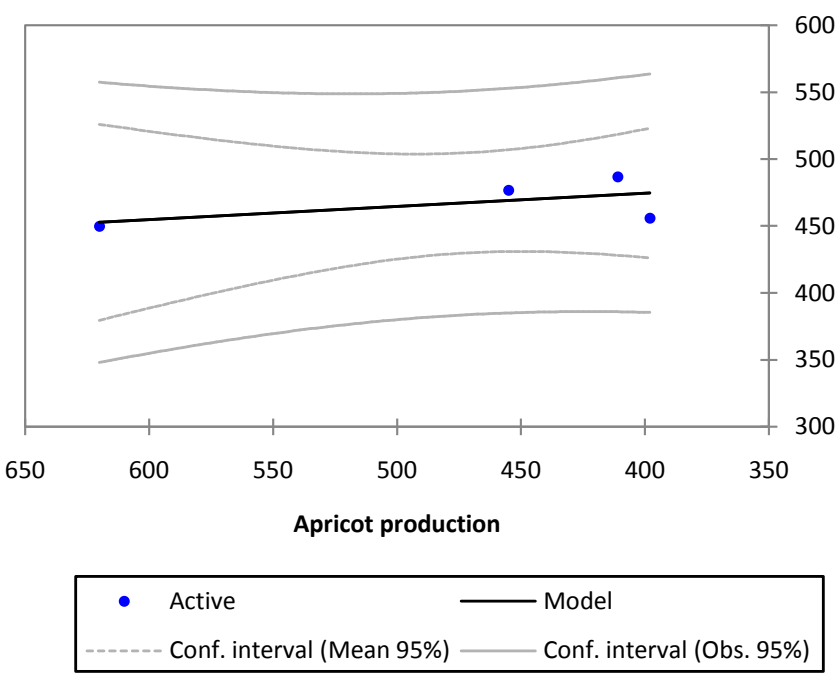

(e)

Df / Standardized coefficients

(95\% conf. interval)

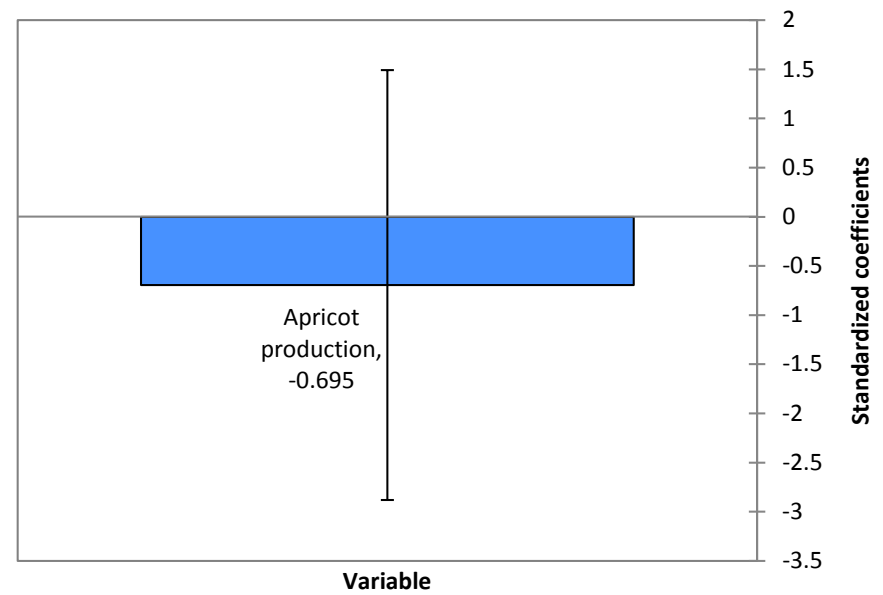

(f) 
[5] Ighbareyeh, J.M.H., Cano-Ortiz, A., Suliemieh, A.A.A., Ighbareyeh, M.M.H. and Cano, E. (2014) Phytosociology with Other Characteristic Biologically and Ecologically of Plant in Palestine. American Journal of Plant Sciences, 5, 3104-3118. https://doi.org/10.4236/ajps.2014.520327

[6] Ighbareyeh, J.M.H., Cano-Ortiz, A., Suliemieh, A.A.A., Ighbareyeh, M.M.H. and Cano, E. (2015) Assessing Crop Yield Sustainability under the Climatic and Bioclimatic Change in the Area of Palestine. American Journal of Climate Change, 4, 48-56. https://doi.org/10.4236/ajcc.2015.41005

[7] Cano-Ortiz, A., Ighbareyeh, J.M.H. and Cano E. (2014) Bioclimatic Applications and Soil Indicators for Olive Cultivation (South of the Iberian Peninsula). Global Advanced Research Journal of Agricultural Science, 3, 433-438.

[8] Ighbareyeh, J.M.H., Cano-Ortiz, A., Suliemieh, A.A.A., Ighbareyeh, M.M.H. and Cano, E. (2015) Study of Biology and Bioclimatology of Date Palm (Phoenix Dactylifera L.) to Optimize Yield and Increase Economic in Jericho and Gaza Cities of Palestine. International Journal of Research Studies in Biosciences, 3, 1-8. http://www.arcjournals.org

[9] Ighbareyeh, J.M.H., Cano-Ortiz, A., Suliemieh, A.A.A., Ighbareyeh, M.M.H. and Cano, E. (2015) Assessment of Biology and Bioclimatology of Plant to Increase Economic in Palestine. International Journal of Research Studies in Biosciences, 3, 1-8. http://www.arcjournals.org

[10] Ighbareyeh, J.M.H., Cano-Ortiz, A., Suliemieh, A.A.A., Ighbareyeh, M.M.H. and Cano, E. (2015) Biology and Bioclimatology Applied on Plant in Palestine. International Journal of Research Studies in Biosciences, 3, 79-86.

http://www.arcjournals.org

[11] Ighbareyeh, J.M.H., Cano-Ortiz, A., Suliemieh, A.A.A., Ighbareyeh, M.M.H. and Cano, E. (2015) Study Effect of Biology and Bioclimatology Applied on Plant in the Area of Hebron at the South of Palestine. International Journal of Research Studies in Biosciences, 3, 56-64. http://www.arcjournals.org

[12] Ighbareyeh, J.M.H., Cano-Ortiz, A., Suliemieh, A.A.A., Ighbareyeh, M.M.H. and Cano, E. (2015) Effect of Biology and Bioclimatology Applied on Plant in the Area of Jenin at the North of Palestine. International Journal of Research Studies in Bioscience, 3, 1-6.

[13] Ighbareyeh, J.M.H., Cano-Ortiz, A., Suliemieh, A.A.A., Ighbareyeh, M.M.H. and Cano, E. (2015) Study of Climatology and Bioclimatology Applied on Plant in Area of Hebron in Palestine. International Multidisciplinary Research Journal, 5, Issue-1/July-2015, ISSN No: 2231-5063.

[14] Ighbareyeh, J.M.H., Cano-Ortiz, A., Cano Carmona, E., Ighbareyeh, M.M.H. and Suliemieh, A.A.A. (2015) Modeling of Biology and Bioclimatology Applied on Plant in Palestine. Swift Journal of Agricultural Research, 1, 21-27. http://www.swiftjournals.org/sjar

[15] Ighbareyeh, J.M.H., Cano-Ortiz, A., Suliemieh, A.A.A., Ighbareyeh, M.M.H. and Cano, E. (2015) Effect of Biology and Bioclimatology Applied Studies on Plant in the Area of Jerusalem in Palestine. International Journal of Research Studies in Biosciences, 3, 135-140. http://www.arcjournals.org

[16] Ighbareyeh, J.M.H., Cano-Ortiz, A., Cano, E., Ighbareyeh, M.M.H. and Suliemieh, A.A.A. (2016) Effect of Biology, Climatic and Bioclimatic Applied Studies on Plant: To Increase the Economy and Maintaining Food Security in the Jerusalem Occupied of Palestine. International Journal of Research Studies in Biosciences, 4, 54-60. http://www.arcjournals.org 
[17] Ighbareyeh, J.M.H., Cano-Ortiz, A., Suliemieh, A.A.A., Ighbareyeh, M.M.H. and Cano, E. (2016) Study of Biology and Bioclimatology Applied of Apricot (Prunus armeniaca L.): To Increase the Economy and Maintaining Food Security in Palestine. International Journal of Research Studies in Biosciences, 4, 12-20. http://www.arcjournals.org

[18] Ighbareyeh, J.M.H., Cano-Ortiz, A., Suliemieh, A.A.A., Ighbareyeh, M.M.H. and Cano, E. (2016) Modeling of Biology and Bioclimatology Applied Studies on Plant in Palestine. International Journal of Development Research, 6, 9585-9590. http://www.journalijdr.com

[19] Ighbareyeh, J.M.H., Cano-Ortiz, A., Suliemieh, A.A.A., Ighbareyeh, M.M.H., Cano, E. and Shahir, H. (2016) Effect of Bioclimate Factors on Olive (Olea europea L.) Yield: To Increase the Economy and Maintaining Food Security in Palestine. International Journal of Development Research, 6, 10648-10652. http://www.journalijdr.com

[20] Ighbareyeh, J.M.H., Cano-Ortiz, A., Cano Carmona, E., Ighbareyeh, M.M.H., Suliemieh, A.A.A. and Shahir, H. (2017) Impact of Bioclimate and Climate Factors on Plant Yield in the Area of Jenin at the North of Palestine. International Journal of Current Research, 9, 44529-44535.

[21] Ighbareyeh, J.M.H., Cano Ortiz, A. and Cano, E. (2014) Biological Resources Management in Palestine. Doctorate Thesis, Department of Animal and Plant Biology and Ecology, Faculty of Experimental Sciences, University of Jaen, Jaen, 100-105.

[22] Ighbareyeh, J.M.H., Cano-Ortiz, A., Carmona, E.C., Suliemieh, A.A.A. and Ighbareyeh, M.M.H. (2017) Flora Endemic Rare and Bioclimate of Palestine. Open Access Library Journal, 4, e3977. https://doi.org/10.4236/oalib.1103977

[23] United Nation Food and Agriculture Organization (2013) Production of Apricot by Countries.

[24] Palestinian Central Bureau of Statistics (PCBS) (2009). http://pcbs.gov.ps/Downloads/book1620.pdf

[25] Leathwick, J.R., Overton, J.M. and McLeod, M. (2003) An Environmental Domain Classification of New Zealand and Its Use as a Tool for Biodiversity Management. Conservation Biology, 17, 1612-1623. https://doi.org/10.1111/j.1523-1739.2003.00469.x

[26] Sayre, R., Comer, P., Warner, H. and Cress, J. (2009) A New Map of Standardized Terrestrial Ecosystems of the Conterminous United States. US Geological Survey Professional Paper 1768, US Geological Survey, Reston.

[27] Sitch, S., Smith, B., Prentice, I.C., Arneth, A., Bondeau, A., Cramer, W., Kaplan, J.O., Levis, S., Lucht, W., Sykes, M.T., Thonicke, K. and Venevsky, S. (2003) Evaluation of Ecosystem Dynamics, Plant Geography and Terrestrial Carbon Cycling in the LPJ Dynamic Vegetation Model. Global Change Biology, 9, 161-185.

https://doi.org/10.1046/j.1365-2486.2003.00569.x

[28] Thuiller, W., Lavorel, S., Araujo, M.B., Sykes, M.T. and Prentice, I.C. (2005) Climate Change Threats to Plant Diversity in Europe. Proceedings of the National Academy of Sciences USA, 102, 8245-8250.

https://doi.org/10.1073/pnas.0409902102

[29] Rivas-Martínez, S., Rivas-Sáenz, S. and Penas, A. (2011) Worldwide Bioclimatic Classification System. Global Geobotany, 1, 1-634.

[30] Rivas Martinez, S., Sanchez Mata, D. and Costa, M. (1999) North American Boreal and Western Temperate Forest Vegetation (Syntaxonomical Synopsis of the Potential Natural Plant Communities of North America, II). Itinera Geobotanica, 12, 
5-316.

[31] Rivas Martínez, S. (1996) Clasificación bioclimática de la Tierra. Folia Bot. Matritensis., Vol. 16, 1-20.

[32] Rivas Martinez, S. (2004) Worldwide Bioclimatic Classification System. http://www.globalbioclimatics.org

[33] Rivas-Martinez, S. (2008) Global Bioclimatic. http://www.globalbioclimatics.org

[34] Shapiro, S. and Wilk, M. (1965) An Analysis of Variance Test for Normality (Complete Samples). Biometrika, 52, 591-611. https://doi.org/10.1093/biomet/52.3-4.591

[35] Shapiro, S., Wilk, M. and Chen, H. (1968) A Comparative Study of Various Tests for Normality. Journal of the American Statistical Association, 63, 1343-1372. https://doi.org/10.1080/01621459.1968.10480932

[36] Jarque, C. and Bera, A. (1980) Efficient Tests for Normality Homoscedasticity and Serial Independence of Regression Residuals. Econometric Letters, 6, 255-259. https://doi.org/10.1016/0165-1765(80)90024-5

[37] Jarque, C. and Bera, A. (1987) A Test for Normality of Observations and Regression Residuals. International Statistical Review, 55, 163-172. https://doi.org/10.2307/1403192

[38] Pearson, K. (1895) Notes on Regression and Inheritance in the Case of Two Parents. Proceedings of the Royal Society of London, 58, 240-242. https://doi.org/10.1098/rspl.1895.0041

[39] Stigler, S.M. (1989) Francis Galton's Account of the Invention of Correlation. Statistical Science, 4, 73-79. 